DOI: 10.17805/ggz.2018.1.2

\title{
Цифровое общество в свете культурологии
}

\author{
T. Ф. Кузнеиова
}

Московский педагогический государственный университет

В статье рассматриваются тенденции внедрения циирровой экономики в России и возникающие разногласия в обществе по этому поводу. В силу направленности концепции цифрового общества в будущее показано, что вне учета культурных факторов она теряет свою многомерность, которая нужна человеку для жизни в обществе будущего. С опорой на тезаурусный подход подчеркивается, что контрфорсом технократизации иифровой экономики в системе образования выступает гуманитаризация образования.

Ключевые слова: иифровое общество; иифровая экономика; культурология; тезаурусньй подход; будущее; гуманитаризащия образования

\section{Digital Society through the Lens of Culturology}

\author{
T. F. Kuznetsova \\ Moscow State Pedagogical University
}

The article examines trends in digital economy implementation in Russia and emergent controversies in the society on this point. Considering the orientation of the concept of digital society to the future, the author shows that it loses its multidimensionality without reference to cultural factors while a human being needs this pluridimensionality for living in the future society. Based on the thesaurus approach, the study notes that the counterforce to the technocratization of digital economy in the educational system is the humanitarization of education.

Keywords: digital society; digital economy; culturology; thesaurus approach; future; humanitarization of education

\section{ВВЕДЕНИЕ}

Появление в оптимистическом облачении идеи цифровой экономики, а затем и цифрового общества предполагает не только переосмысление инструментов экономического развития России в ближайшие годы, но и обновление целого ряда сопутствующих социокультурных процессов, прежде всего всей системы высшего образования, которая должна отвечать на вызовы цифровой экономики в содержании обучения и в его результативности, а это 
не может не затрагивать не только состав действующих в стране вузов, их внутренние и внешние связи (основу рейтинга по представляемым как объективные показателям и престижа - по субъективным), но и состав факультетов в них, направленность филиалов, качество профессорско-педагогического состава, качество набора студентов на всех формах обучения и т. д.

Но это часть стоящей задачи. Еще летом 2017 г. председатель правительства Российской Федерации Д. А. Медведев подчеркивал (а это значит, что руководство страны планирует соответствующие действия): «Очевидно, что структура экономики в эпоху цифрового развития, масштабного перехода к “цифре” в качестве носителя информации, конечно, сильно меняется, и, наверное, это должно находить свое отражение и в корректировках законодательства», а также и следующее: «Мы не можем использовать прежние критерии и антимонопольного регулирования, и вообще прежние подходы к законодательному регулированию целого ряда устоявшихся гражданскоправовых конструкций и в области договорного права, и в области регистрации права собственности и других прав на недвижимость, ну и, наконец, в области антимонопольного регулирования» (Медведев ... , 2017: Электронный ресурс).

Итак, крупные перемены в организации и управлении экономикой видятся в специфике самой этой экономики, а значит, и общества, для которого она предназначена и которое она призвана развивать. Справедливо в этом контексте употреблять понятие «цифровое общество» как выражающее его суть. Но в чем эта суть? В настоящей статье технократические трактовки цифрового общества, которые наполнены оптимизмом и сопровождаются активными действиями, сопоставляются с недоверием к ним, вытекающим из распространенной среди россиян культурной картиной мира. Характер возникающего культурного конфликта и пути его преодоления составляют цель статьи.

\section{КОНЦЕПЦИЯ ЦИФРОВОГО ОБЩЕСТВА: КАКИМ В НЕЙ ВИДИТСЯ БУДУЩЕЕ}

28 июля 2017 г. Правительство Российской Федерации распоряжением премьер-министра Д. А. Медведева № 1632-р утвердило программу «Цифровая экономика Российской Федерации». Целями программы определены: а) создание экосистемы цифровой экономики Российской Федерации, в которой данные в цифровой форме являются ключевым фактором производства во всех сферах социально-экономической деятельности и в которой обеспечено эффективное взаимодействие, включая трансграничное, бизнеса, научно- 
образовательного сообщества, государства и граждан; б) создание необходимых и достаточных условий институционального и инфраструктурного характера, устранение имеющихся препятствий и ограничений для создания и (или) развития высокотехнологических бизнесов и недопущение появления новых препятствий и ограничений как в традиционных отраслях экономики, так и в новых отраслях и высокотехнологичных рынках; в) повышение конкурентоспособности на глобальном рынке как отдельных отраслей экономики Российской Федерации, так и экономики в целом (Программа «Цифровая экономика Российской Федерации», 2017: Электронный ресурс).

В определении понятия «цифровая экономика» очевидно представление лиц, принимающих управленческие решения в масштабах страны, о характере грядущего общества. По их мнению, «цифровая экономика представляет собой хозяйственную деятельность, ключевым фактором производства в которой являются данные в цифровой форме, и способствует формированию информационного пространства с учетом потребностей граждан и общества в получении качественных и достоверных сведений, развитию информационной инфраструктуры Российской Федерации, созданию и применению российских информационно-телекоммуникационных технологий, а также формированию новой технологической основы для социальной и экономической сферы» (там же). Соответственно видятся и социокультурные факторы обновления: «С использованием цифровых технологий изменяются повседневная жизнь человека, производственные отношения, структура экономики и образование, а также возникают новые требования к коммуникациям, вычислительным мощностям, информационным системам и сервисам» (там же). В чем состоят эти новые требования?

Применительно к сфере образования они таковы (надо учитывать, что образование отнесено к числу базовых направлений развития цифровой экономики): «Основными целями направления, касающегося кадров и образования, являются: создание ключевых условий для подготовки кадров цифровой экономики; совершенствование системы образования, которая должна обеспечивать цифровую экономику компетентными кадрами; рынок труда, который должен опираться на требования цифровой экономики; создание системы мотивации по освоению необходимых компетенций и участию кадров в развитии цифровой экономики России» (там же). При этом в констатирующей части документа подчеркнуто, что в российской системе образования расширяется применение цифровых технологий. Отмечено, что образовательные организации имеют выход в сеть Интернет и представлены там на своих сайтах «в соответствии с государственными требованиями», а также и 
то, что нормативно, технологически и содержательно обеспечен курс информатики и информационно-коммуникационных технологий в программах общего образования, ведется подготовка кадров для цифровой экономики. «Однако численность подготовки кадров и соответствие образовательных программ нуждам цифровой экономики недостаточны. Имеется серьезный дефицит кадров в образовательном процессе всех уровней образования. В процедурах итоговой аттестации недостаточно применяются цифровые инструменты учебной деятельности, процесс не включен целостно в цифровую информационную среду» (там же).

Но есть и прямо противоположная трактовка столь масштабной социальной и культурной инновации. В этой трактовке цифровое общество предстает не только в пессимистических, но и прямо в катастрофических для человечества и населения России, в частности, красках.

Доклад одного из лидеров движения «За право жить без ИНН, личных кодов и микрочипов» В. П. Филимонова на XXVI Международных Рождественских чтениях (секция «Актуальные вопросы национального суверенитета России», Москва, 26 января 2018 г., Российский университет дружбы народов) выразительно назывался «Цифровое общество и конец истории». В нем подчеркивалось, что цифровое общество - это «глобальный проект, целью которого является построение нового рабовладельческого общества, управляемого посредством использования информационно-коммуникационных технологий, основанных на применении микроэлектроники, локальных и глобальных компьютерных сетей, которые собирают, обрабатывают, генерируют и распределяют информацию через системы глобальных телекоммуникационных сетей. Поэтому цифровое общество, по сути своей, является сетевым информационным обществом» (Филимонов, 2018: Электронный ресурс).

Можно считать, что агиография (а это богословская дисциплина, изучающая жития святых, богословские и историко-церковные аспекты святости, что прямо вытекает из толкования греческого термина, сочетающего ä $\gamma 10 \varsigma$ - «святой» и үра́ $\varphi \omega-$ «пишу») и не увидит в цифровом обществе его светлые стороны, а писатель-агиограф В. П. Филимонов выражает именно такой взгляд на формирующееся общество. Но правильнее заметить, что технократическая трактовка цифрового общества недостаточна, одностороння и не придает значения отдаленным последствиям его утверждения в мире и стране, что замечают критики идеи, руководствующиеся гуманистическими, христианскими идеалами.

В том же духе следует посмотреть на публикации, где цифровое общество приравнивается к информационному. Такую позицию занимал, напри- 
мер, известный советский грузинский ученый в области теории процессов и систем управления, информатики и вычислительной техники И. В. Прангишвили (1930-2006), возглавлявший в 1987-2006 гг. Институт проблем управления им. В. А. Трапезникова РАН. В книге «Энтропийные и другие системные закономерности: Вопросы управления сложными системами», где были представлены энтропийные модели сложных систем и энтропийные расчеты при управлении производственными и бизнес-процессами (Прангишвили, 2003), он осмысливал в свете системного подхода пути выхода России из структурного и системного кризиса, свойства современного общества и проблемы его развития. При этом он исходил из понимания общесистемных закономерностей функционирования технических и социальных систем (он считал их основными и объективными), в том числе энтропийного равновесия, и предлагал свое определение методов управления энтропийными колебаниями, энтропийным равновесием и избыточной энтропией. Исследуя новые системные закономерности зависимости потенциала систем от структуры систем, он выдвигал идеи резонансного управления и анализировал сложные искусственные и природные системы и вопросы их управления. На фоне этих положений, важных для управления экономикой, И. В. Прангишвили подчеркивал, что «в мире происходит вторая промышленная революция, изменяя коренным образом способы производства материальной продукции и услуг. Вторую революцию иногда называют информационной, электронно-цифровой или компьютерной» (Прангишвили: Электронный ресурс), и это общество трактуется через его признаки, которые видятся в следующем: 1) ориентация на знания; 2) цифровая форма представления объектов; 3) виртуализация производства; 4) инновационная природа развития; 5) интеграция и глобализация, 6) конвергенция и динамизм; 8) трансформация отношений изготовитель-потребитель; 9) широкое и разнообразное применение Интернета и ряд др. (там же). Хотя это довольно узкое представление об обществе будущего, оно неоднократно повторено. В итоге распространено достаточно умозрительное и периферийное для авторских целей книги об управлении экономикой понимание цифрового общества, исходящее скорее из догадок и предположений автора, чем из того, что к такому обществу во всех странах — с развитой экономикой и нет - ведет переходный период, каждый раз разный и учитывающий, среди прочего, культурные факторы (историю, государственность, исторические личности, мифологизацию достигнутого и утерянного и т.д.). Более адекватное представление встречаем в книге Вал. А. Лукова и Э. К. Погорского «Информационное общество и молодежь», где авторы рассматривают не схему и не ожидания, а 
ситуацию постепенного входа в этот тип общества России. Авторы пишут: «Становление информационного общества в мире и России выражается прежде всего в усилении роли информации в организации и регулировании на всех уровнях социальности общественной жизни, а также в существенном обновлении коммуникационных процессов. Это обновление происходит как по форме, так и по содержанию: по мере освоения новых форм, определяемых развитием новых средств и технологий коммуникации, сама коммуникация становится неузнаваемой даже в пределах ближайших поколений» (Луков, Погорский, 2014: 16). Для российской вариации выделяются признаки изменений, хорошо показанные в структуре первой главы. Приведем ее. Авторы отмечают формирующийся в обществе, стремящемуся к информационному типу, приоритет информации и коммуникации; показывают человека в сетевом пространстве; выявляют виртуальность в Происходящем; особо выделяют субъективное исчезновение пространства и времени; сопоставляют одновременно присутствующие в нем инновационность и архаизацию; выявляют новые условия социализации; показывают информационный аспект глобализации; демонстрируют компьютеризацию школы как начальный этап вхождения России в информационное общество; показывают ориентацию на информационное общество в концепциях информационной политики России.

Некоторые положения И. В. Прангишвили и аналогичные предвидения других авторов надо, конечно, учитывать, планируя путь к цифровому обществу. В частности, увязывание быстрого развития цифрового общества в одних странах при других темпах или ином понимании сути общества будущего в других с агрессивными компенсационными процессами планетарного масштаба. «В богатых странах через средства массовой информации ежедневно внушалось, что ради обогащения надо быть сильным, жестким, хитрым, не жалеть никого, можно стать циником и аморальным человеком. Допускалось добывание денег спекулятивным путем или любыми другими способами, кроме преступного. Глобализация экономики и информатизация общества богатых делает еще богаче, а бедных еще беднее. Все это пробуждает у обездоленных зависть, ярость, нетерпимость, стремление отомстить всем и каждому богатому, порождает терроризм, как один из способов мщения», отмечает И. В. Прангишвили (Прангишвили: Электронный ресурс).

\section{КУЛЬТУРОЛОГИЧЕСКАЯ ТРАКТОВКА ЦИФРОВОГО ОБЩЕСТВА}

Цифровое общество в свете культурологии видится в сочетании оптимистических и пессимистических красок - именно красок, поскольку явля- 
ется предположением, а не логической конструкцией, и относится скорее к концептам, чем к понятиям. Чтобы это утверждение было яснее, подчеркнем методологическую разницу между понятиями в принятом в науке значении и концептами, хотя во многих языках эта разница не видна, а понятие и концепт выступают как полные синонимы и без всяких объяснений заменяют друг друга, например, в целях улучшения стилистики какой-либо статьи или книги.

В тезаурусном подходе к концептам специфическое отношение. Ю. С. Степанов считал, то концепты «это как бы сгусток культуры в сознании человека; то, в виде чего культура входит в ментальный мир человека. И, с другой стороны, концепт - это то, посредством чего человек - рядовой, обычный человек, не “творец культурных ценностей” — сам входит в культуру, а в некоторых случаях и влияет на нее. <..> В отличие от понятий в собственном смысле термина... концепты не только мыслятся, они переживаются. Они - предмет эмоций, симпатий и антипатий, а иногда и столкновений. Концепт - основная ячейка культуры в ментальном мире человека» (Степанов, 2004: 43). Именно в смысле Ю. С. Степанова в тезаурусном подходе концепт определяется как «выражаемое в знаке сращение смысла и чувственного восприятия, внутреннего образа. Его связывает с другими концептами не только логическое, но и ценностное отношение» (Луков В., Луков Вл., 2013: 75). В трактовке концепта важным представляется обратить внимание на следующее разъяснение Вал. А. и Вл. А. Луковых: «...что же такое концепт - понятие или образ? И в какой мере это структура сознания? Видимо, балансировать на грани между понятием и образом - одно из свойств концепта как особой структурной формы сознания» (там же).

Цифровое общество, понимаемое как концепт, требует ценностного измерения, хотя ему (как аналогу общества будущего) могут быть присущи противоречия, которые сейчас оцениваются в пределах отдельных направлений (например, в области цифровой экономики, которая пока не может решить вопросы о биткоинах, хотя первый выпуск этой самой популярной в мире цифровой валюты относится к 2009 г., т. е. уже скоро десятилетие, что при скоростях XXI в. очень много) или даже фрагментов. Если принять ценностную шкалу цифрового общества, то разделение оптимистического и пессимистического взглядов станет в высшей степени контрастным. Если выбрать первый вариант, то и в культурологическом отношении вскроются перспективные черты этого общества, а негативные черты окажутся приглушенными. Надо сказать, что это прагматический подход к будущему, он не бежит от задач постсовременности, но он видит культурные изменения как важную 
составную часть общего движения в будущее, не сводимое только к цифровой экономике.

Изменения при таком подходе касаются гораздо большей сферы общественной жизни, включая повседневность, производственные отношения, структуру экономики и образование и т. д. Соответственно предстоят большие перемены во всех частях гуманитарной сферы. Это относится в особой мере к системе образования, которая рассматривается как одно из базовых направлений развития цифровой экономики.

Образование составляет основу успешного продвижения России в мировой цифровой экономике, а в конечном счете и к цифровому обществу. Это не может не породить противоречия и проблемы перехода образования к новому качеству, в том числе отказ от целостности в пользу узкой специализации; признание образования, основанного на технократической модели, более современным и более эффективным; ориентацию на образование в странах с продвинутой цифровой экономикой с его системой ценностей. В этих направлениях видятся главные вызовы для сложившейся в России системы образования.

На фоне проблем и противоречий, которые несет цифровое пространство российской системе образования, основное значение приобретает тенденция к гуманитаризации образовательного процесса на всех его уровнях и во всех формах. Неверно было бы ослаблять цифровую составляющую этого процесса, поскольку миросистемная конкуренция переходит из сферы экономики в сферу культуры и цифровое образование не дает защиты национальной безопасности в этом сегменте. Гуманитаризация и составляет контрфорс технократическому отношению к системе образования и дает возможность, не теряя направленность системы в будущее, не отказываться от достигнутого Россией в сфере образования.

\section{ЗАКЛЮЧЕНИЕ}

Привязывание цифрового общества к цифровой экономике порождает технократический взгляд на будущее, и его оптимизм, во-первых, временный и, во-вторых, легко может перейти в пессимизм, как только на биржах начинается непрогнозируемая скачка цен. В оболочке ценностных отношений, которая изучается культурологией, особенно культурологией субъектной (Луков, 2008), в центре которой стоит социальная субъектность во всех ее формах - от индивидуальной до присущей человечеству, представления о цифровом обществе приобретают многомерность. Именно ее надо передавать в системе образования новым поколениям, которым и предстоит конструиро- 
вать будущее. Гуманитаризация образования в этом ракурсе приобретает новый смысл, поскольку культурная картина мира (Кузнецова, 2012, 2015; Погорский, 2012) в XXI в. существенно меняется. Чтобы она опиралась на устойчивые элементы сознания целых народов, недостаточны меры в области экономики, они должны быть подкреплены культурным наследием в режиме содействия, противодействия, параллельного независимого движения - эта линия в любом случае создает ту многомерность, которая имеет человеческую ориентацию, соразмерна многообразию повседневных практик и может уберечь человечество от неоправданных шатаний, которые на поверхности ощущаются в виде распадения традиционной морали. Здесь в теоретических построениях есть необходимость опереться на тезаурусный подход, а в практической деятельности на несколько ослабленную в последнее время гуманитаризацию образования, которая придаст новый импульс воспитанию новых поколений, не разрушая, а поддерживая его наполненную человеческими радостями и страстями жизнь в цифровом обществе.

В этом направлении и предстоит перестраивать образовательный процесс в средней и высшей школе, ориентируясь на актуальные для России задачи в области цифровой экономики.

\section{СПИСОК ЛИТЕРАТУРЫ}

Кузнецова, Т. Ф. (2012) Культурная картина мира: теоретические проблемы. М. : ГИТР. 250 с.

Кузнецова, Т. Ф. (2015) Культурная картина мира как ядро тезауруса в концепции Владимира Андреевича Лукова [Электронный ресурс] // Информационный гуманитарный портал «Знание. Понимание. Умение». № 3 (май — июнь). C. 5-16. URL: http://zpu-journal.ru/e-zpu/2015/3/Kuznetsova_CulturalWorld-View/ [архивировано в WaybackMachine] (дата обращения: 15.02.2018).

Луков, В. А., Луков, Вл. А. (2013) Тезаурусы II: Тезаурусный подход к пониманию человека и его мира. М. : Изд-во Моск. гуманит. ун-та. 640 с.

Луков, В. А., Погорский, Э. К. (2014) Информационное общество и молодежь : науч. монография / Моск. гуманит. ун-т. Ин-т фундамент. и приклад. исследований. М. : Изд-во Моск. гуманит. ун-та. 160 с.

Луков, Вл. А. (2008) Культурология объектная и субъектная // Знание. Понимание. Умение. № 1. С. 72-79.

Медведев: цифровая экономика требует корректировки законодательства (2017) [Электронный ресурс] // TACC. 27 июня. URL: http://tass.ru/ekonomika/4368611 [архивировано в WaybackMachine] (дата обращения: 15.02. 2018).

Погорский, Э. К. (2012) Картина мира // Знание. Понимание. Умение. № 4. С. 322-323. 
Прангишвили, И. В. (2003) Энтропийные и другие системные закономерности: Вопросы управления сложными системами / Рос. акад. наук. Ин-т проблем упр. им. В. А. Трапезникова. М. : Наука. 428 с.

Прангишвили, И. В. Энтропийные и другие системные закономерности: Вопросы управления сложными системами [Электронный ресурс] // Персональный сайт Аполова Олега Геннадиевича. URL: http://apolovoleg.narod.ru/olderfiles/1/Prangishvili_I.V_JEntropiinye_i_dr-88665.pdf [архивировано в WaybackMachine] (дата обращения: 15.02.2018).

Программа «Цифровая экономика Российской Федерации». (2017) Утверждена распоряжением Правительства Российской Федерации от 28 июля 2017 г. № 1632-р [Электронный ресурс] // Правительство России. URL: http://static.government.ru/media/files/9gFM4FHj4PsB79I5v7yLVuPgu4bvR7M0. pdf [архивировано в WaybackMachine] (дата обращения: 15.02.2018).

Степанов, Ю. С. (2004) Константы : Словарь русской культуры. 3-е изд., испр. и доп. М. : Академ. проект. 991 с.

Филимонов, В. П. (2018) Цифровое общество и конец истории [Электронный ресурс] // РИА «Катюша». 1 февраля. URL: http://katyusha.org/ view?id=9326 [архивировано в WaybackMachine] (дата обращения: 15.02. 2018).

Дата поступления: 19.02.2018 г.

Кузнецова Татьяна Федоровна - доктор философских наук, професcop; профессор кафедры культурологии Московского педагогического государственного университета, академик Международной академии наук (Инсбрук, Австрия). Адрес: 119571, Москва, проспект Вернадского, д. 88. Тел.: +7 (495) 539-55-19. Эл. адрес: kult@mpgu.edu

Kuznetsova Tatiana Fedorovna, Doctor of Philosophy, Professor, Department of Culturology, Moscow State Pedagogical University; Full member, International Academy of Science (IAS, Innsbruck, Austria). Postal address: 88 Prospekt Vernadskogo, 119571 Moscow, Russian Federation. Tel.: +7 (495) 539-55-19. E-mail: kult@mpgu.edu

\section{Для циитирования:}

Кузнецова T. Ф. Цифровое общество в свете культурологии [Электронный ресурс] // Горизонты гуманитарного знания. 2018. № 1. C. 27-36. URL: http://journals.mosgu.ru/ggz/article/view/700 (дата обращения: дд.мм.гггг). DOI: 10.17805/ggz.2018.1.2 